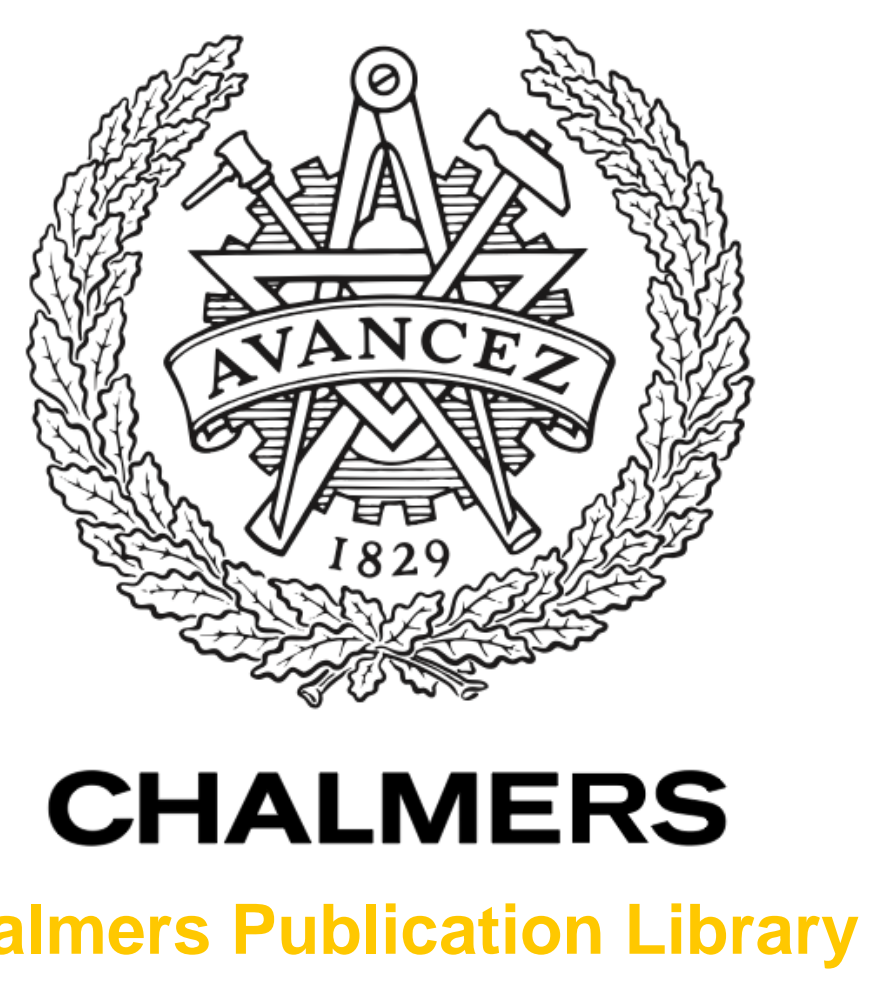

Challmers Publication Library

\title{
Enantioselective Cyclization of Photochromic Dithienylethenes Bound to DNA
}

This document has been downloaded from Chalmers Publication Library (CPL). It is the author's version of a work that was accepted for publication in:

\section{Angewandte Chemie-International Edition (ISSN: 1433-7851)}

Citation for the published paper:

Pace, T. ; Muller, V. ; Li, S. (2013) "Enantioselective Cyclization of Photochromic

Dithienylethenes Bound to DNA". Angewandte Chemie-International Edition, vol. 52(16), pp. 4393-4396.

http://dx.doi.org/10.1002/anie.201209773

Downloaded from: http://publications.lib.chalmers.se/publication/177447

Notice: Changes introduced as a result of publishing processes such as copy-editing and formatting may not be reflected in this document. For a definitive version of this work, please refer to the published source. Please note that access to the published version might require a subscription. 


\title{
Enantioselective cyclization of photochromic dithienylethenes bound to
}

\author{
Tamara C. S. Pace, Vilhelm Müller, Shiming Li, Per Lincoln and Joakim Andréasson*
}

Since the majority of the DNA mediated processes occurring in our cells can be inhibited by molecules binding to the double helix, photoactivation of the DNA binding process would provide a dramatically improved spatiotemporal control over the action of many biochemical processes. With this idea as the inspiration, the DNA binding properties of a number of photochromic systems have recently been studied. $^{[1]}$ A spiropyran, ${ }^{[1 \mathrm{a},}$ 1b] a chromene, ${ }^{[1 \mathrm{c}]}$ and a benzothiazoloquinolinium ${ }^{[1 \mathrm{~d}]}$ have all been shown to have only one form of the photochromic molecule that interacts with DNA and DNA binding can therefore be modulated by irradiation. Conversely, both the isomers of a dithienylethene (DTE) derivative were shown to bind to DNA with similar binding affinities. ${ }^{[1 \mathrm{e}]}$ The typical derivative from the DTE photochromic family can be reversibly switched between the open and closed forms with high fatigue resistance and no thermal isomerization. ${ }^{[2]}$ Photocyclization to the closed form of DTE produces two enantiomers, which are usually found as a racemic mixture in solution. Enrichment of one enantiomer for a symmetrically substituted DTE has previously only been reported in single crystals, where two types of crystals formed, each consisting of only one conformer of the open DTE, which could subsequently be isomerized to the corresponding closed form with high enantioselectivity. ${ }^{[3]}$ Diastereoselectivity, however, has been more readily obtained for DTEs using chiral, and often bulky, substituents in solution, ${ }^{[4]}$ in gels, ${ }^{[5]}$ or in single crystals. ${ }^{[6]}$

In solution, inclusion of achiral photoreactants in chiral supramolecular systems has been used to influence the chirality of the products for photocyclizations, photoisomerizations, photodimerizations or photoadditions in systems including cyclodextrins, ${ }^{[7]}$ modified zeolites, ${ }^{[8]}$ and proteins. ${ }^{[9]}$ Though stereoselective binding to DNA is commonly observed, and DNA has been used to indirectly transfer chirality through an asymmetric catalyst in ground state reactions, ${ }^{[10]}$ there is only one reported example using DNA to directly influence the chiral outcome of a photoreaction, where Wada et al. observed modest enantiomeric excesses for the photoisomerization of

[*] Dr. T. C. S. Pace, V. Müller, Dr. S. Li, Prof. Dr. P. Lincoln and Prof. Dr. J. Andréasson

Department of Chemical and Biological Engineering,

Physical Chemistry

Chalmers University of Technology

41296 Göteborg Sweden

Fax: (+)46 317723858

E-mail: a-son@chalmers.se

[**] This work was supported by the Swedish Research Council (grant 622-2010-280) and the European Research Council (ERC FP7/2007-2013 grant No. 203952).

Supporting information for this article is available on the WwW under http://www.angewandte.org or from the author. cyclooctene when complexed with DNA. ${ }^{[11]}$ Here, we report the binding of a methylpyridinium- and a methylquinoliumappended DTE to DNA and the achievement of enantioselectivity for the closing reaction of the methylquinolium DTE derivative in the presence of DNA. This is a rare example of direct transfer of chirality from DNA to a photoproduct and it is also the first reported example of enantioselectivity for a DTE derivative in solution.

DTE symmetrically substituted with methylpyridinium chloride (1) or methylquinolium chloride (2) groups (Scheme 1) were synthesized as described in the Supporting Information. The permanent positive charges due to methylation of the heterocyclic nitrogens lead to good water solubility of both 1 and 2. The open forms $\mathbf{1 0}$ and $\mathbf{2 0}$ absorb exclusively in the UV region (Figure 1). Isomerization to the closed form is triggered by UV light. Following isomerization with $366 \mathrm{~nm}$ UV light the photostationary states were determined from ${ }^{1} \mathrm{H}$ NMR spectra to be $>98 \%$ 1c for 1 and ca. 92/8 2c/2o for 2. The closed forms 1c and 2c have significant absorption in the visible region (Figure 1), and reverse isomerization using broadband visible light $(\lambda>$ $530 \mathrm{~nm}$ ) converts both 1 and 2 to $100 \%$ open form. No thermal interconversion was observed over weeks at ambient temperature.

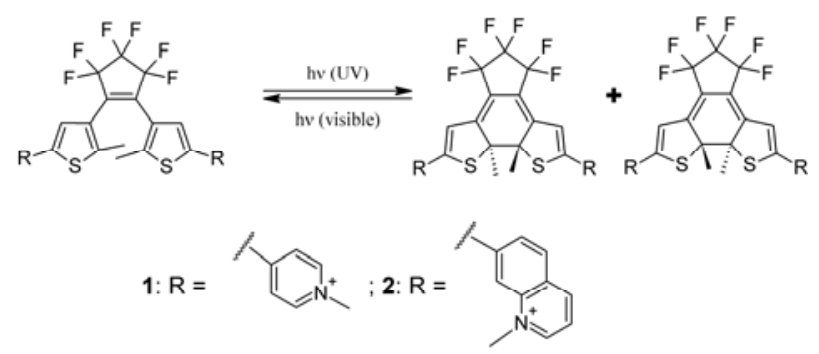

Scheme 1. Dithienylethenes $\mathbf{1}$ and $\mathbf{2}$ in the open form and in the closed form with enantiomers of $S, S$ or $R, R$ configuration.

Changes in the absorption spectra of both the open and closed forms of $\mathbf{1}$ and $\mathbf{2}$ on addition of calf thymus DNA (ctDNA) indicated that both isomers of these DTE derivatives bind to DNA. Similarly an amine terminated DTE has been previously shown to bind to DNA in both forms when protonated. ${ }^{[1 e]}$ The changes in the absorption spectra for both isomeric forms of $\mathbf{1}$ and $\mathbf{2}$ on addition of $c t$-DNA are similar. An initial decrease in the absorption was seen with no change in the wavelength of the absorption maxima at high DTE/DNA ratios, while on further addition of DNA a red shift in the absorption maximum and an increase in the absorption was observed (Figure S1 in the Supporting Information). This behavior is indicative of more than one type of binding interaction between each DTE and $c t$-DNA (see assignment below). 

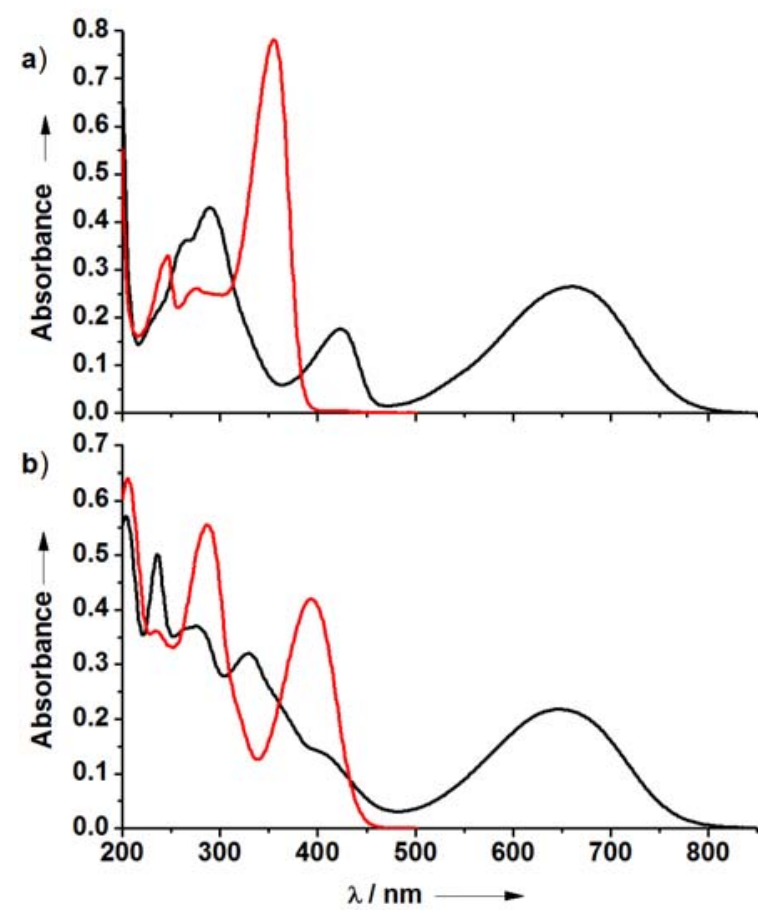

Figure 1. UV/Vis absorption spectra in $5 \mathrm{mM} \mathrm{NaCl}$ of (a) 10 (red) and 1c (black) and (b) 20 (red) and 2c (black).

In order to show circular dichroism (CD) molecules must be inherently chiral or be perturbed by a chiral environment. In solution the achiral open form of symmetric DTEs or the racemic mixture $(S, S+R, R)$ of the chiral closed form show no CD signal, however when bound to DNA induced CD signals are observed. CD titrations showed an increase in signal on addition of $c t$-DNA to DTE for both isomers of $\mathbf{1}$ and 2 (Figure 2 and 3 for $\mathbf{2 o}$ and 2c; Figure S2 and S3 in the Supporting Information for $\mathbf{1 0}$ and 1c). Only specific binding interactions such as groove binding or intercalation will give rise to a strong CD signal. Unlike the UV titrations above, the CD titrations showed no obvious indication of multiple binding modes between the DTEs and $c t$-DNA. We therefore assign the behavior observed at high DTE/DNA ratios in the absorption titrations to electrostatic binding of the positively charged $\mathbf{1}$ or $\mathbf{2}$ with the negative phosphate backbone of DNA, as such non-specific interactions are likely to contribute little to the CD spectra. The second binding mode observed at low DTE/DNA ratios in the absorption titrations is the binding observed in the CD spectra, which we assign to a specific binding interaction between the DTE and DNA. Non-specific binding is likely to have little effect on the chiral outcome of the DTE closing reaction and we expect any observed enantioselectivity (see below) to arise from intercalative or groove binding interactions, especially at the relatively high DNA concentration used where the specific binding mode predominates.

Apparent binding constants for the specific binding mode were estimated from the CD titrations assuming a 1:1 binding stoichiometry per DNA base pair (see Supporting Information for details). Binding constants of $(5.0 \pm 0.1) \mathrm{x}$ $10^{5} \mathrm{M}^{-1}$ and $(2.3 \pm 0.1) \times 10^{5} \mathrm{M}^{-1}$ were obtained for 10 and 1c, respectively, and binding constants of $(2.8 \pm 0.5) \times 10^{5} \mathrm{M}^{-}$
${ }^{1}$ and $(7.6 \pm 1.1) \times 10^{5} \mathrm{M}^{-1}$ were obtained for $2 \mathrm{o}$ and $2 \mathrm{c}$, respectively.

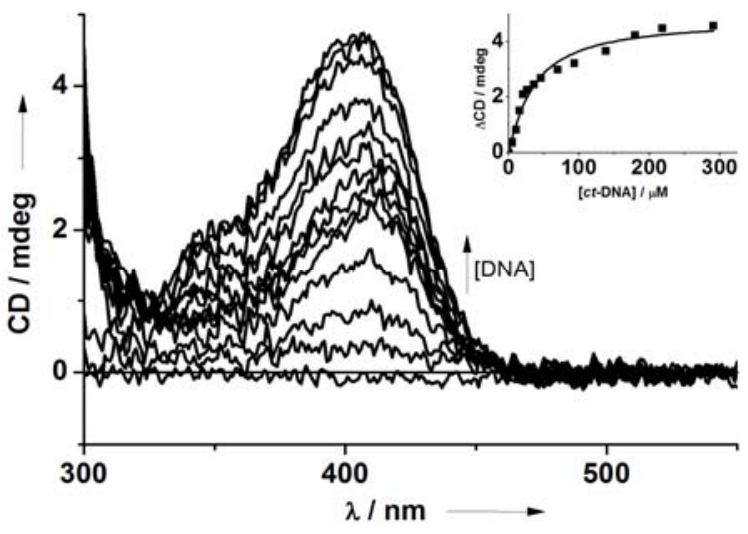

Figure 2. $\mathrm{CD}$ spectra of $20(15.5 \mu \mathrm{M})$ in $5 \mathrm{mM} \mathrm{NaCl}$ in the presence of increasing concentrations of ct-DNA $(0-290 \mu \mathrm{M}$ b.p.) (inset: binding isotherm at $405 \mathrm{~nm}$ for the binding of 20 to ct-DNA fit to eq. S1 in the Supporting Information).

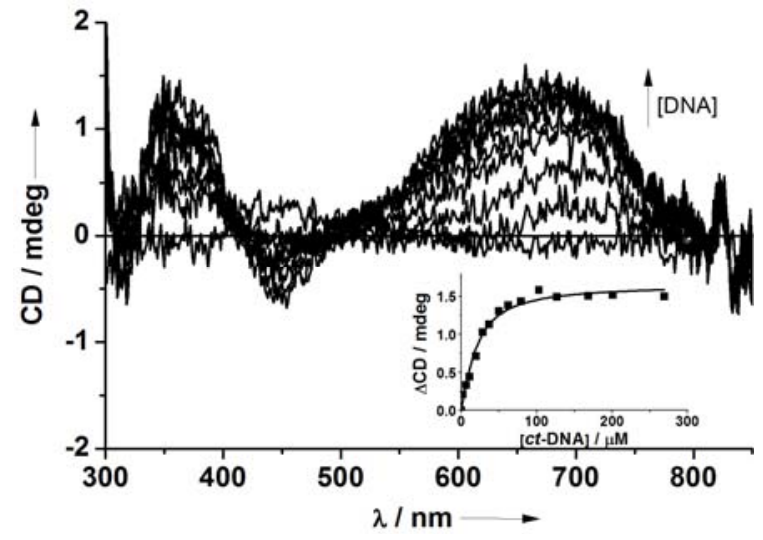

Figure 3. $\mathrm{CD}$ spectra of $2 \mathrm{c}(14.3 \mu \mathrm{M})$ in $5 \mathrm{mM} \mathrm{NaCl}$ in the presence of increasing concentrations of ct-DNA $(0-270 \mu \mathrm{M}$ b.p.) (inset: binding isotherm at $675 \mathrm{~nm}$ for the binding of 2c to ct-DNA fit to eq. $\mathrm{S} 1$ in the Supporting Information).

In flow oriented linear dichroism (LD) experiments DNA is oriented in a shear flow and any LD signal from the DTE is due to specific binding to DNA. The sign of the LD signal contains valuable information about the orientation of the DTE relative to DNA. Molecules that interact with DNA through intercalation between the base pairs exhibit only negative bands in the LD spectra, whereas molecules that bind in the DNA groove tend to have both negative and positive LD bands. ${ }^{[12]}$ Inspection of the LD spectra shows only negative bands for 10, while both negative and positive bands were seen for 1c (Figure 4a). This observation shows that the interaction of $\mathbf{1 0}$ with $c t$-DNA is intercalative, while 1c interacts with $c t$-DNA through groove binding. Only negative bands were observed in the LD spectra of $\mathbf{2 0}$ and $\mathbf{2 c}$ (Figure 4b), demonstrating that both isomers of 2 interact with $c t$-DNA through intercalation. The binding mode of the closed forms is also supported by a comparison of the intensity of the bands in the LD spectra with those in the corresponding isotropic absorption spectra (see Supporting Information). 


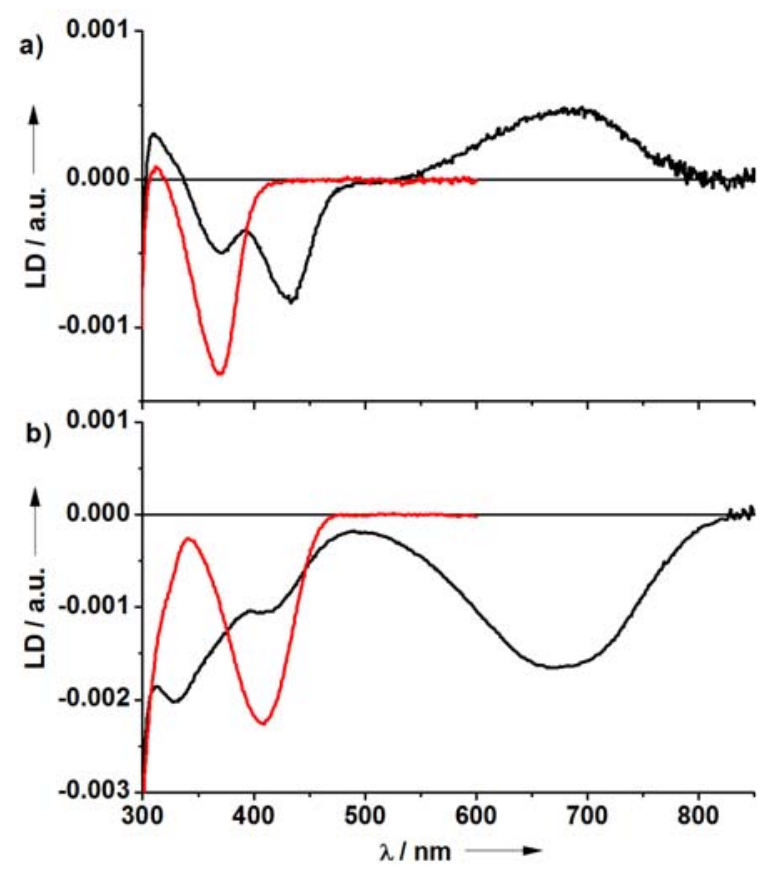

Figure 4. (a) LD spectra for 10 (red) and 1c (black) $(18 \mu \mathrm{M})$ in $5 \mathrm{mM}$ $\mathrm{NaCl}$ with $200 \mu \mathrm{M}$ ct-DNA. (b) LD spectra for $2 \mathrm{o}$ (red) $(14 \mu \mathrm{M})$ and $2 \mathrm{c}$ (black) $(13 \mu \mathrm{M})$ in $5 \mathrm{mM} \mathrm{NaCl}$ with $175 \mu \mathrm{M}$ ct-DNA.

The observed rate of the closing reaction is not significantly changed in the presence of DNA. Thus, although binding is a dynamic process, isomerization of $\mathbf{1}$ and 2 can easily occur while bound to DNA without dissociation from the double helix. However, a remarkable difference was observed between the CD spectra obtained for a sample of $\mathbf{2}$ where racemic $\mathbf{2 c}$ was formed in bulk solution then added to DNA, and for a sample where the closing reaction 2o $\rightarrow$ 2c was carried out in the presence of DNA (Figure 5a). The sample that was isomerized in the absence of DNA displays a positive CD band centered at $668 \mathrm{~nm}$ when DNA is added. This CD signature is assigned to the induced CD from the racemic solution of $\mathbf{2 c}$ when bound to DNA. In sharp contrast, the sample that was isomerized in the presence of DNA displays only a very weak CD signal. This observation implies that closing 20 in the presence of DNA does not lead to the formation of racemic $\mathbf{2 c}$, but instead to the preferential formation of one of the enantiomers of 2c. The inherent $\mathrm{CD}$ signal of the favored enantiomer must be of opposite sign to that of the CD signal induced by DNA binding, resulting in the apparent disappearance of the long wavelength band in the CD spectra for the latter solution.

SDS micelles were added to the above solutions to extract 2 from DNA. Following addition of SDS the solution containing racemic $\mathbf{2 c}$ had no CD activity (red line in Figure $5 b)$, as expected for complete extraction of $\mathbf{2}$ from DNA. On the other hand, the solution where $\mathbf{2 c}$ was formed in the presence of DNA showed a significant negative CD signal following extraction from DNA (black line in Figure 5b). This inherent CD signal confirms that this solution has an excess of one of the enantiomers of 2c. Further irradiation of this extracted solution with visible light to form 20 and subsequent UV irradiation to reform $2 \mathbf{c}$ led to the disappearance of the $\mathrm{CD}$ signal, i.e., the enantioselectivity achieved when $\mathbf{2}$ is bound to DNA is lost following isomerization in bulk solution. Unfortunately, to date, attempts to separate the enantiomers and quantify the enantiomeric excess achieved have not been successful.

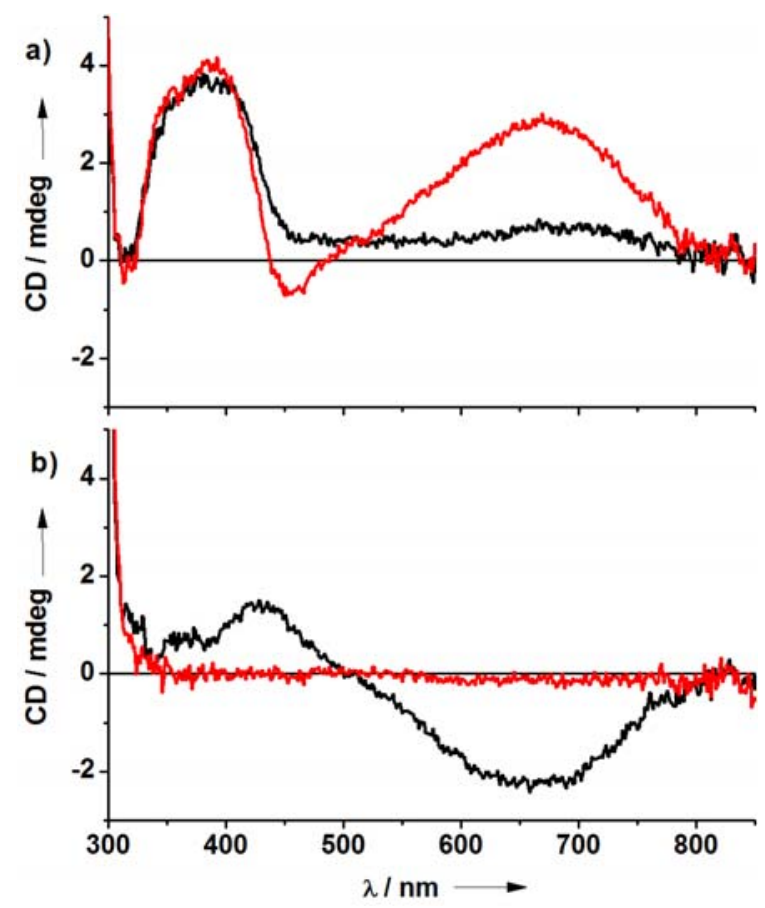

Figure 5. (a) CD spectra of $2(50 \mu \mathrm{M})$ closed with $366 \mathrm{~nm}$ light in bulk solution then added to $480 \mu \mathrm{M} c t$-DNA (red) and closed with $366 \mathrm{~nm}$ light in the presence of $480 \mu \mathrm{M}$ ct-DNA (black). (b) CD spectra of above solutions on addition of $50 \mathrm{mM}$ SDS.

For $\mathbf{1}$ no difference was observed for the CD spectra of $\mathbf{1 c}$ bound to DNA when the closing reaction was carried out in the absence or presence of DNA (Figure S4 in the Supporting Information), indicating that no significant enantioselectivity is achieved for the $\mathbf{1 0} \rightarrow \mathbf{1 c}$ reaction in the presence of DNA. Previously, a similar experiment with a DTE that underwent photoisomerization to the closed form while included in a cyclodextrin cavity showed no indication of enantiomer enrichment. ${ }^{[13]}$

The conformers of the DTE open form undergo fast exchange in solution, resulting in the formation of a racemic mixture of the closed form on photocyclization. The observed enantioselectivity of the photocyclization of $\mathbf{2}$ in the presence of DNA indicates either that one conformer of $2 \mathbf{0}$ is preferentially bound to DNA or that when bound one conformer is more easily able to undergo isomerization to 2c. The binding affinities for both forms of $\mathbf{1}$ and $\mathbf{2}$ with $c t$-DNA are of a similar magnitude and the main difference in the interaction of $\mathbf{1}$ and $\mathbf{2}$ with DNA is that the binding modes of $2 \mathrm{o}$ and $\mathbf{2 c}$ are the same (intercalation), while $\mathbf{1 o}$ and $\mathbf{1 c}$ have different binding modes (intercalation and groove-binding, respectively). The fact that enantioselectivity is achieved for the closing reaction of $\mathbf{2}$ but not for $\mathbf{1}$ could be explained by this difference in binding modes. Since the binding mode of $\mathbf{1}$ changes during isomerization it seems likely that this would lead to a disruption of the interaction of $\mathbf{1}$ with the chiral environment of DNA when moving along the reaction coordinate from $\mathbf{1 o}$ to $\mathbf{1 c}$. This would not be the case for $\mathbf{2}$ where isomerization may occur freely within the chiral environment of the double helix. Consequently, chirality 
transfer from DNA occurs in the case of 2, but not in the case of 1.

In summary, we report two water soluble, positively charged DTEs, which bind to ct-DNA in both the open and closed forms. Significant enantioselectivity was observed for the DTE closing reaction for the DTE that interacts with DNA through intercalation in both forms. The observed enantiomeric enhancement in this system is a rare realization of direct chirality transfer from DNA. Moreover, using this approach to affect the chiral outcome of the DTE photocyclization allowed us to obtain enantioselectivity for symmetric DTE derivatives in solution for the first time.

Received: ((will be filled in by the editorial staff))

Published online on ((will be filled in by the editorial staff))

Keywords: dithienylethenes - DNA binding • enantioselectivity * photochromism · supramolecular chemistry Soc. 2008, 130, 11836-11837; b) M. Hammarson, J. Andersson, S. Li, P. Lincoln, J. Andréasson, Chem. Commun. 2010, 46, 71307132; c) S. V. Paramonov, V. Lokshin, H. Ihmels, O. A. Fedorova, Photochem. Photobiol. Sci. 2011, 10, 1279-1282; d) D. Berdnikova, O. Fedorova, E. Gulakova, H. Ihmels, Chem. Commun. 2012, 48, 4603-4605; e) A. Mammana, G. T. Carroll, J. Areephong, B. L. Feringa, J. Phys. Chem. B 2011, 115, 1158111587.

[2] a) M. Irie, Chem. Rev. 2000, 100, 1685-1716; b) H. Tian, S Yang, Chem. Soc. Rev. 2004, 33, 85-97.

[3] S. Yamamoto, K. Matsuda, M. Irie, Angew. Chem. 2003, 115, 1674-1677; Angew. Chem. Int. Ed. 2003, 42, 1636-1639. a) T. Yamaguchi, K. Uchida, M. Irie, J. Am. Chem. Soc. 1997, 119, 6066-6071; b) T. Shiozawa, M. K. Hossain, T. Ubukata, Y. Yokoyama, Chem. Commun. 2010, 46, 4785-4787; c) Y. Tani, T. Ubukata, Y. Yokoyama, Y. Yokoyama, J. Org. Chem. 2006, 72, 1641-1644; d) T. J. Wigglesworth, D. Sud, T. B. Norsten, V. S. Lekhi, N. R. Branda, J. Am. Chem. Soc. 2005, 127, 7272-7273.

[5] J. J. D. de Jong, L. N. Lucas, R. M. Kellogg, J. H. van Esch, B. L. Feringa, Science 2004, 304, 278-281.

[6] a) T. Kodani, K. Matsuda, T. Yamada, S. Kobatake, M. Irie, J. Am. Chem. Soc. 2000, 122, 9631-9637; b) K. Uchida, M. Walko, J. J. D. de Jong, S.-i. Sukata, S. Kobatake, A. Meetsma, J. van Esch, B. L. Feringa, Org. Biomol. Chem. 2006, 4, 1002-1006.

[7] a) Y. Inoue, F. Dong, K. Yamamoto, L. H. Tong, H. Tsuneishi, T. Hakushi, A. Tai, J. Am. Chem. Soc. 1995, 117, 11033-11034; b) A. Nakamura, Y. Inoue, J. Am. Chem. Soc. 2003, 125, 966-972; c) V. P. Rao, N. J. Turro, Tetrahedron Lett. 1989, 30, 4641-4644.

[8] A. Joy, J. R. Scheffer, V. Ramamurthy, Org. Lett. 2000, 2, 119121.

[9] a) M. Nishijima, T. Wada, T. Mori, T. C. S. Pace, C. Bohne, Y. Inoue, J. Am. Chem. Soc. 2007, 129, 3478-3479; b) T. Wada, M. Nishijima, T. Fujisawa, N. Sugahara, T. Mori, A. Nakamura, Y. Inoue, J. Am. Chem. Soc. 2003, 125, 7492-7493.

[10] a) G. Roelfes, Mol. Biosyst. 2007, 3, 126-135; b) G. Roelfes, B. L. Feringa, Angew. Chem. 2005, 117, 3294-3296; Angew. Chem. Int. Ed. 2005, 44, 3230-3232.

[11] T. Wada, N. Sugahara, M. Kawano, Y. Inoue, Chem. Lett. 2000, 1174-1175.

[12] a) B. Norden, M. Kubista, T. Kurucsev, Q. Rev. Biophys. 1992, 25, 51-171; b) B. Norden, T. Kurucsev, J. Mol. Recog. 1994, 7, 141-156.

[13] M. Takeshita, N. Kato, S. Kawauchi, T. Imase, J. Watanabe, M. Irie, J. Org. Chem. 1998, 63, 9306-9313. 


\section{Entry for the Table of Contents}

\section{((Catch Phrase))}

Tamara C. S. Pace, Vilhelm Müller, Shiming Li, Per Lincoln, Joakim Andréasson* Page - Page

Enantioselective cyclization of photochromic dithienylethenes bound to DNA

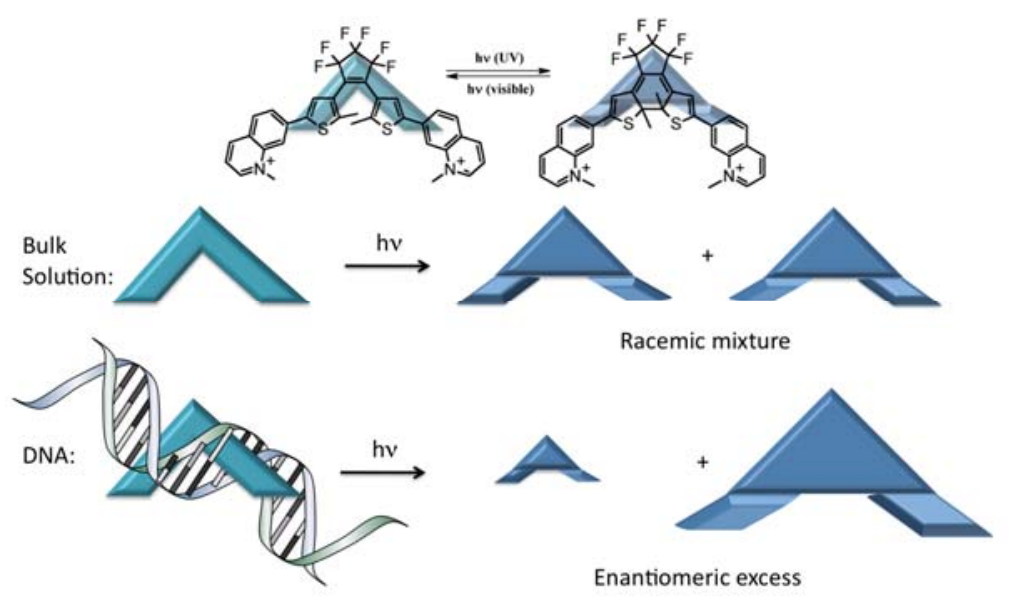

Chirality Transfer: Enantioselectivity is obtained for the photocyclization of a photochromic dithienylethene when isomerization is carried out in the presence of DNA. 